\title{
Preliminary assessment of the impacts of human activities on gorillas Gorilla gorilla gorilla and other wildife at Dzanga-Sangha Reserve, Central African Republic
}

\author{
Melissa J. Remis
}

\begin{abstract}
The aim of this study was to make preliminary assessments of the effects of human activities on the gorillas and other wildlife in the Dzanga-Ndoki Park and broader Dzanga-Sangha Dense Forest Reserve (RDS), Central African Republic. During a month-long survey in 1997, observation and sign of humans and large mammals, including ape nest-sites, were recorded on $81.2 \mathrm{~km}$ of line transects in three sectors of the park and reserve. Human activities, including intensities of logging and hunting, appeared to decrease with distance from the population centres and were lower in the park than in the reserve sectors. Encounter rates with sign of duikers Cephalophus spp., monkeys Cercopithecus spp. and Cercocebus albigena, elephants Loxodonta africana, and gorillas Gorilla gorilla gorilla were generally lower in regions of high human activity in the reserve than in the park sectors. Nevertheless, gorilla nest-site
\end{abstract}

densities did not vary significantly between sectors or with human activity levels. A high frequency of zero (bare ground) nests at RDS suggests that gorilla surveys that rely on line transect methods and use nest decomposition rates from other studies may sometimes underestimate gorilla densities. This study suggests that current levels of exploitation in managed hunting zones of national forest reserves may be negatively affecting targeted wildlife populations in these zones. Assessments should be a regular part of efforts to monitor the health of wildlife populations in managed protected zones. Participation by Central Africans in research will continue to benefit conservation and development efforts.

Keywords Conservation, duikers, elephants, hunting, primates, survey methods.

\section{Introduction}

Central African forests and their wildlife are under increasing pressure from immigration, logging, agriculture, mining and hunting, even in areas that are slated for protection under integrated conservation and development projects (ICDP) (Oates, 1995; Bryant et al., 1997; Noss, 1997). The Dzanga-Sangha Forest Reserve (RDS), Central African Republic, was developed as an ICDP (Alpert, 1996). It aims to link conservation with community development by designating multiple-use zones within the protected region, and managing conflicts between biodiversity conservation and local resource use. Integrated conservation and development projects have been criticized for pursuing economic and social development at the expense of adequate wildlife preservation measures (Robinson, 1993; Oates, 1995). The RDS has struggled to develop both ecotourism and wildlife protection, but neither programme has met with a high degree of success, in part as a result of an unstable

Melissa J. Remis Department of Sociology and Anthropology, Purdue University, West Lafayette, IN 47907-1365, USA.

Fax + 1765496 1476; E-mail: remism@sri.soc.purdue.edu political climate. Moreover, the project has not been viewed by the growing local community as successful in providing adequate alternatives to logging income or bushmeat (Noss, 1997). Although wildlife populations at RDS still exist at relatively high densities, this reserve may soon become an example of how our understanding of the consequences of human disturbance is insufficient to ensure maintenance of biodiversity within the context of rapid human economic development.

Throughout the central African region, wildlife is the primary source of protein for human populations (Asibey, 1974; Fitzgibbon et al., 1995; Struhsaker, 1997). As human populations grow, duikers and other preferred bushmeat species may decline in abundance (Noss, 1997), with primates being increasingly exploited for local consumption and export to urban markets (Auzel \& Wilkie, in press). Primates, particularly apes, are large bodied and slow to reproduce; even moderate hunting pressure on these species may be unsustainable (Kano \& Asato, 1994; Harcourt, 1996; Oates, 1996). Surveys in 1984 in the south-western Central African Republic reported high population densities of western lowland gorillas and forest elephants (Carroll, 1988; Fay, 1989). The study reported here provides follow-up information on the status of gorillas and other large mammals within the Dzanga-Sangha Forest Reserve (RDS). 
Efforts to monitor wildlife are complicated by the difficulties inherent in observing and censusing tropical forest species. Nevertheless, anti-poaching efforts in isolation of wildlife assessment may not provide adequate protection; they do not take into account the multiple effects of human activities on those species that are slated for conservation.

The aim of this study was to make preliminary assessments of the effects of varying human activities on the wildlife in the Dzanga-Ndoki Park and the broader RDS (see also Carroll, 1988; Fay, 1989; Remis \& Mbassangao, 1998). The focus of this study was Gorilla gorilla gorilla and the large mammals that are the primary targets of hunters in the region. The study took place over one month (July 1997), building on a foundation of more than 4 years of data collection on the reserve. This study also served as a training vehicle for Central African University students. It has implications for improving both local research capacity and conservation management efforts across the Central African region.

\section{Methods}

The study was conducted within the Dzanga-Ndoki park and reserve sectors of RDS $\left(4200 \mathrm{sq} \mathrm{km}, 2^{\circ} 13^{\prime} 26^{\prime \prime} \mathrm{N}\right.$, $\left.16^{\circ} 11^{\prime} 26^{\prime \prime} \mathrm{E}\right)$. Rainfall in the reserve averages approximately $1400 \mathrm{~mm}$ per year (Remis, 1997). The survey of wildlife and human activities was conducted just prior to the peak rainy period (August-October). The methods adopted for data collection and analysis were modified from techniques used to estimate wildlife densities in previous studies (Tutin \& Fernandez, 1984; Hall et al., 1998). During the census, a total of $81.2 \mathrm{~km}$ was surveyed. Three 30-sq-km sample blocks were selected within the Dzanga park sector of RDS and surrounding managed reserve (Fig. 1). Three trained research teams surveyed six variable width and length $(4-5 \mathrm{~km}$ ) line transects (at the rate of $1 \mathrm{~km}$ per h) in each block for wildlife and human sign (Whitesides et al., 1988).

The survey blocks were located at varying distances from the population centre of Bayanga (population c. 3000 people), the location of both the National Park Headquarters and Sylvicole (formerly Slovenia-Bois) logging operations. The national park and reserve were gazetted in 1990 but conservation and anti-poaching activities started in the area in 1987. Between 1975 and 1982, many areas within RDS, including the sample blocks, were selectively logged at low levels (typically Entrandrophragma spp. were logged at 1-2 stems per ha) by Slovenia Bois. At that time, hunting camps were common throughout the area (R. W. Carroll, A. Mbalanga \& E. Wonga, pers. comms.). Currently, only research and tourism are permitted within the park.
Gathering and traditional spear, cross-bow and net hunts and regulated shotgun hunting are permitted within the surrounding, managed hunting reserve sectors. The use of cable snares and the killing of elephants Loxodonta africana, gorillas, chimpanzees Pan troglodytes troglodytes and leopards Panthera pardus are outlawed throughout the country (Carroll, 1997).

The Bai Hokou Study Area $(\mathrm{BH})$, a gorilla research camp since 1987, was selected as the park sample, $30 \mathrm{~km}$ from Bayanga. The Kongana block (KG) was located within the reserve sector, c. $35 \mathrm{~km}$. from Bayanga. The Mabongo stream (MB) was used as the base-camp for a second reserve sector sample block, c. $10 \mathrm{~km}$ from Bayanga (Fig. 1).

Despite the intermittent presence of researchers and park guards at the Bai Hokou site over the last 10 years, we found remains of a freshly killed bongo Tragelaphus eurycerus and a duiker Cephalophus callipygus close to the camp. The Kongana Camp Site was vacated by researchers 1 year prior to this study. When we arrived, the camp was occupied by hunters. During our 9-day stay, we heard heavy rifles being fired on at least four occasions. We also observed three parties of hunters (one travelling by moped) with rifles, and carrying more than 10 Cephalophus spp. carcasses and baskets of unidentified butchered meat.

The Sylvicole logging company had prospected the feasibility of re-logging the Mabongo sector several months prior to this study. Our transects crossed one of the logging company camps as well as two recently vacated hunting camps; other active camps were located nearby. Our camp site was adjacent to a heavily used forest footpath to the closest BaAka village, $c .7 \mathrm{~km}$ away. During the 8 days spent in this sector, we saw more than 30 people carrying snares and baskets of meat and other forest products on the transects, road and footpaths in the reserve and adjacent park zones.

During the survey, transect lines were situated in each block, each following a compass bearing, perpendicular to major drainage features, and at $1-\mathrm{km}$ intervals along baselines (abandoned logging roads) that were parallel to major drainage features. Transects were of variable width and length. A hipchain was used to measure length.

At each change of forest type along transects, habitats were characterized as belonging to one of seven types: (1) monodominant Gilbertodendrion dewverei; (2) primary forest with large trees $>50 \mathrm{~cm}$ d.b.h. and open understory; (3) mixed primary and secondary forest; (4) secondary dense forest with thick understory and vine tangles; (5) roadside; (6) riverine; or (7) clearings (see also Carroll, 1988; Goldsmith, 1996). For each sector, the mean proportion of length of each habitat type encountered per transect was calculated and reported in Table 1. 
Gorilla and chimpanzee tracks, food remains or dung, elephant and ungulate dung, and monkey sightings and calls were recorded on each transect. All indications of human activity and presence were noted. For example, on the transects, sightings of people, tracks, footpaths, machete cut-marks, snares and shotgun shells, active or abandoned camp sites, as well as roads, stumps, cut trails and tree tags were recorded. All human traces, animal dung or feeding remains of a particular species and age, found within a $5-\mathrm{m}$ radius of each other were scored as a single occurrence.

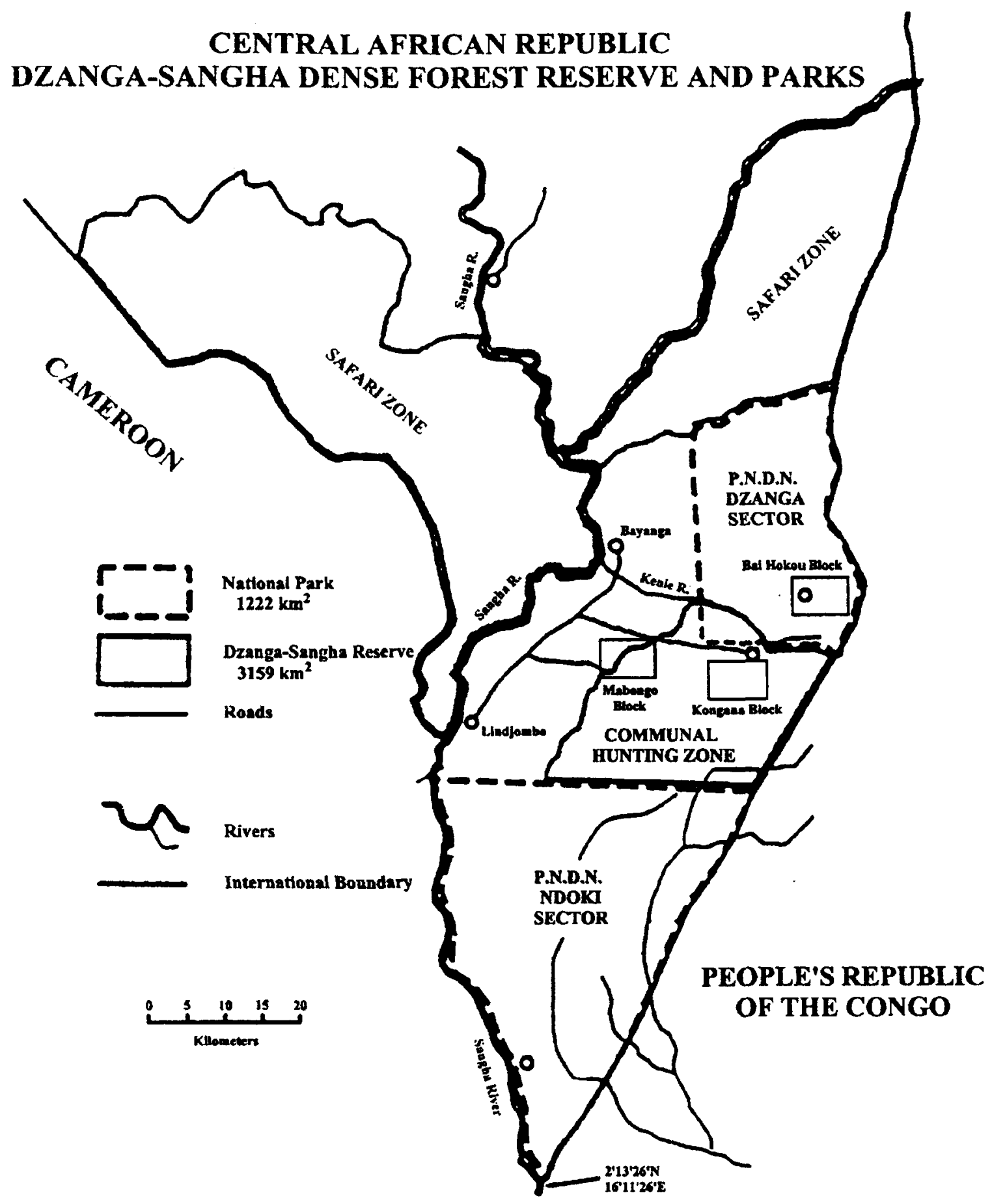

Fig. 1 Map of the study area, Dzanga-Sangha Reserve, Central African Republic. 
Table 1 Percentages of habitat types on transects at Dzanga-Sangha Reserve, Central African Republic, 1997

\begin{tabular}{lllllr}
\hline Site & Primary + mixed & Dense & Roadside & Monodominant & Streams \\
\hline Bai Hokou (30 km park) & 46.9 & 39.5 & 4.1 & 4.6 & 3.8 \\
Kongana (35 km reserve) & 37.4 & 53.4 & 1.9 & 6.4 & 1.1 \\
Mabongo (10 km reserve) & 27.6 & 42.4 & 16.2 & 4.0 & 0.4 \\
\hline
\end{tabular}

Gorilla and chimpanzee nest-sites visible from each transect were mapped and individual nests were counted. Nest construction type (zero or bare ground nests where gorillas sleep without constructing a nest, minimum, herbaceous, mixed, tree [see Remis, 1993]) and perpendicular distance of individual nests to transects were recorded. Relative ages were assigned to nests: Fresh ( $<4$ days), Very Recent ( 4 days -2 weeks), Recent ( 2 weeks -1 month), Old ( $1-2$ months), Very Old (older than 2 months) (Tutin \& Fernandez, 1984; Remis, 1993; Hall et al., 1998).

Weaned chimpanzees and gorillas make one sleeping nest per night, which can be reliably distinguished from day nests or night nests where individuals did not sleep. Nest-sites were scored as G. g. gorilla when at least one ground nest was present and obvious gorilla sign of the same age as the nest-site was found on the ground below the site (Tutin et al., 1995; Hall et al., 1998).

The computer program DISTANCE (Laake et al., 1994) was used to estimate gorilla nest-site densities. The density of weaned individual gorillas was calculated following Tutin \& Fernandez (1984) and modified by Remis (1993) and Hall et al. (1998). This formula multiplies the estimated nest group density by the mean group size, and then divides by the mean nest decay time to give the density of weaned individuals. Only fresh and very recent nest-sites were used to estimate mean group size because the differential disappearance of some nests in older nest-sites may lead to underestimates of group size (Remis, 1993; Tutin et al., 1995).

Mean nest-site decay time is an important variable in the calculation of density estimates, but was not conducted during this short study. In order to estimate nest-site duration at RDS, nest decay rate studies from Gabon (Tutin \& Fernandez, 1984; Tutin et al., 1995) were used in conjunction with known information about local nest-site construction patterns from longterm study of the gorillas at Bai Hokou (Remis, 1993; see also Hall et al., 1998).

Overall differences in human or wildlife encounter rates (numbers of sign per $\mathrm{km}$ walked) or gorilla density were evaluated using non-parametric KruskalWallis tests (Siegel \& Castellan, 1988). Post hoc pairwise multiple comparisons were conducted using the
Student-Newman-Keuls (SNK) method to determine which pairs of sites differed. When sample sizes were unequal, Dunn's Post hoc tests were performed (SigmaStat, 1999). Differences in median group sizes were evaluated using exploratory statistics and the non-parametric Median Test. $G$ tests $(r \times c$ contingency tables) were conducted to determine whether habitat types occurred in the same proportions along transects in each sector (Sokal \& Rohlf, 1981). All tests were two-tailed.

\section{Results}

\section{Habitat analyses}

The frequency of forest types varied between the three sectors (proportions of forest type per transect, $r \times c$ contingency table $G(w)=160.7, P<0.001$, Table 1). $\mathrm{BH}$ was characterized by a greater proportion of primary and mixed forest than either KG or MB sites, with less dense forest, fewer roads but more light gaps and natural saline 'Bai' clearings. $M B$, on the other hand had considerably more roads and streams, and less primary and mixed forest. KG had a high proportion of dense forest and few roads (between site difference in frequency of habitat types: $G(w)=79.4, P<0.05$, d.f. $=10$, Table 1 ).

\section{Human activity on transects}

Evidence of human activity and hunting varied by sector (Kruskal-Wallis test human activity: $H=13.8$, $P=0.001, \quad$ d.f. $=2$; hunting: $H=13.23, \quad P=0.001$, d.f. $=2$ ). There was less human sign, and in particular, less hunting sign inside the remote national park sector than in the remote reserve (human sign: $\mathrm{BH}-\mathrm{KG}$ $q=3.453, P<0.01$; hunting sign: $\mathrm{BH}-\mathrm{KG} q=4.756$, $P<0.01$, Table 2). Human activity was more abundant at $\mathrm{MB}$, the reserve site closest to villages, than in either sampling zone in the forest interior (SNK differences in human sign encounter rates: $\mathrm{MB}-\mathrm{BH} q=5.236$, $P<0.01, \mathrm{MB}-\mathrm{KG} q=4.303, P<0.01$ ). Nevertheless, although hunting sign was more prevalent at $\mathrm{MB}$ than the $\mathrm{BH}$ park site, the overall frequency of hunting sign at $\mathrm{MB}$ did not differ significantly from $\mathrm{KG}$, the remote reserve site (hunting sign encounters: $\mathrm{MB}-\mathrm{BH} q=$ 
5.047, $P=0.01 ; \mathrm{MB}-\mathrm{KG} q=2.717, \mathrm{NS})$. When transects were examined further, it appeared that the intensity of hunting sign along streamside transects varied by sector (Kruskal-Wallis, $H=7.261, P=0.004$ ). Within the reserve, hunting was more intense along streams at $\mathrm{MB}$ (close to villages) than at those in the remote $\mathrm{KG}$ site (hunting along streams SNK: MB-KG $q=2.777$, $P<0.05$ ) (Table 2).

\section{Wildlife sign encounter rates}

The frequency of elephant dung varied by sector $(H=15.76, P=0.001$, d.f. $=2)$. It was encountered most often at the $\mathrm{BH}$ site and was absent at the MB site (SNK elephant sign encounters: $\mathrm{BH}-\mathrm{MB} q=5.506, P<0.01$; $\mathrm{MB}-\mathrm{KG} q=4.076, \quad P<0.01 ; \mathrm{KG}-\mathrm{BH} \quad q=4.076$, $P<0.01$, Table 3). Duiker sign (dung of Cephalophus monticola, $C$. callipygus, $C$. dorsalis, $C$. nigrifrons and C. sylviculter $)$ varied across sectors $(H=7.6, P=0.035$, d.f. $=2$ ). Duiker sign appeared most common at $\mathrm{BH}$, but did not vary significantly between pairs of sites, perhaps because this sign was only recorded on three of six transects at $\mathrm{BH}$ (duiker sign encounters analysed with Dunn's multiple comparison for unequal group sizes: $\mathrm{BH}-\mathrm{MB} q=2.199$, NS; $\mathrm{BH}-\mathrm{KG} q=0.450, \mathrm{NS}$; Table 3).

Overall, monkey calls (Cercopithecus pogonias, C. nictitans, $C$. cephus and Cercocebus albigena) did not vary significantly by sector $(H=5.608, P=0.078$, d.f. $=2$, Table 3) but were somewhat less frequent at $\mathrm{MB}$ and on at least two occasions monkeys fled silently in this sector.

\section{Gorilla sign and densities}

Gorilla sign (the frequency of food remains, dung and knuckleprints) varied by sector $(H=8.570, P=0.014$, d.f. $=2$ ) and was more frequent at both $\mathrm{BH}$ and $\mathrm{KG}$ than at MB. Differences between $\mathrm{KG}$ and $\mathrm{BH}$ were not significant (SNK gorilla sign encounters: $\mathrm{BH}-\mathrm{MB}$ $q=4.015, \quad P<0.01 ; \quad \mathrm{KG}-\mathrm{MB} \quad q=4.246, \quad P<0.01$; $\mathrm{BH}-\mathrm{KG} q=1.693$, NS; Table 3). Gorilla sign was in- versely correlated with both human activity and hunting rates (Fig. 2, gorilla and human sign: $r=-0.562$, $P<0.01$; gorilla and hunting sign: $r=-0.58, P<0.01$ ).

By contrast to the data for gorilla sign, fewer gorilla nest-sites and nests were found in the park than in the less protected sectors, although differences between sectors did not reach significance (gorilla nest-site encounters: $H=1.903, P=0.386$, d.f. $=2$; gorilla nest encounters: $H=2.857, P=0.240$, d.f. $=2$; Table 3). Chimpanzee nests and nest-sites were rare at all three sites and no significant differences between sectors were found $(H=0.369, P=0.832$, d.f. $=2$, NS, Table 3 ).

\section{Gorilla nest-site encounter rates and density estimates}

A total of 142 nests at 30 gorilla nest-sites was encountered during transect sampling in the three survey blocks, yielding a total nest-site density estimate of 21.6 nest-sites per sq $\mathrm{km}$ (95 per cent $\mathrm{CI}$ : 13-35.4). Gorilla nest-site densities did not vary significantly by sector (nest-site densities: $H=2.594, P=0.273$, d.f. $=2$, Table 4).

Gorilla densities were estimated using three parameters: mean nest-site density, mean group size and mean nest-site decay rate. Because nest-sites were rare along transects, observations for all three sampling blocks were pooled to obtain a sample size adequate for estimating the parameter values of a nest-site detection function (Buckland et al., 1993). Following Buckland et al. (1993) the furthest 5 per cent of data points from the transect were discarded. The effective strip width was calculated by DISTANCE to be $8.4 \mathrm{~m}$.

The mean gorilla group size based on fresh and very recent nest-sites was $4.7(\mathrm{BH}=4, \mathrm{KG}=4, \mathrm{MB}=6.3)$. Median group size for all nest-sites was 4 , and varied between survey blocks $(\mathrm{BH}=2, \mathrm{KG}=4, \mathrm{MB}=6$; Median test $=8.1, P=0.017$, d.f. $=2$ ). In addition, more single nests (attributed to lone males) were detected at $\mathrm{BH}$ than other sites.

Given the unusually high proportion of zero (bare ground) nests recorded during this census (proportion

\begin{tabular}{llll}
\hline & $\begin{array}{l}\text { Bai Hokou (BH) } \\
\text { park }\end{array}$ & $\begin{array}{l}\text { Kongana (KG) } \\
\text { remote reserve }\end{array}$ & $\begin{array}{l}\text { Mabongo (MB) } \\
\text { reserve }\end{array}$ \\
\hline $\begin{array}{llll}\text { No. km surveyed } \\
\text { Distance from Bayanga (km) }\end{array}$ & 29.9 & 25 & 26.3 \\
$\begin{array}{l}\text { Distance to Bai (km) } \\
\text { Mean encounter rate human }\end{array}$ & 0.91 & 35 & 10 \\
$\quad$ sign (per km) & & 5 & $>15 ?$ \\
$\quad$ Imedian] & {$[0.83]$} & 1.7 & 4.4 \\
$\begin{array}{l}\text { Mean encounter rate hunting } \\
\text { sign (per km) }\end{array}$ & 0.07 & {$[1.8]$} & {$[4.6]$} \\
[median] & {$[0]$} & 0.96 & 1.6 \\
\hline
\end{tabular}

Table 2 Human activity patterns on wildlife transects at Dzanga-Sangha Reserve, Central African Republic, 1997 
Table 3 Encounter rates with wildlife sign along transects, Dzanga-Sangha Reserve, Central African Republic, 1997

\begin{tabular}{lccc}
\hline & Bai Hokou $(\mathrm{BH})$ park & Kongana (KG) remote reserve & Mabongo (MB) reserve \\
\hline Mean elephant dung per km & 5.10 & 1.60 & 0 \\
[median] & {$[3.80]$} & {$[1.50]$} & {$[0]$} \\
Mean duiker dung per km & 1.70 & 1.50 & 0.50 \\
[median] & {$[1.90]^{*}$} & {$[1.40]$} & {$[0.33]$} \\
Mean monkey calls per km & 0.91 & 1.10 & 0.60 \\
[median] & {$[0.85]$} & {$[1.20]$} & {$[0.40]$} \\
Mean gorilla sign per km & 6.50 & 5.60 & 3.0 \\
[median] & {$[7.10]$} & {$[5.40]$} & {$[3.30]$} \\
Mean gorilla nest-sites per km & 0.24 & 0.56 & 0.34 \\
[median] & {$[0.19]$} & {$[0.51]$} & {$[0.24]$} \\
Mean gorilla nests per km & 0.95 & 2.20 & 2.20 \\
[median] & {$[1.0]$} & {$[1.47]$} & {$[1.82]$} \\
Chimpanzee nests per $\mathrm{km}$ & 0.30 & 0.60 & 0.42 \\
[median] & {$[0.21]$} & {$[0.13]$} & {$[0.10]$} \\
\hline
\end{tabular}

* Duiker sign was only recorded on three of six transects at Bai Hokou.

zero nests: $\mathrm{BH} 22$ per cent, KG 38 per cent, $\mathrm{MB}$ 37 per cent) and during long-term work at $\mathrm{BH}$ (proportion zero nests 47 per cent of 1231 fresh nests; Remis, 1993) relative to Lopé, Gabon or other sites ( < 3 per cent zero nests; Tutin et al., 1995, also Brugiere et al., 1999), it is difficult to accurately estimate nest decay rates at RDS from the other data sets. Nevertheless, the decay rate at RDS is provisionally estimated by multiplying the construction types of fresh nest-sites from the long-term $\mathrm{BH}$ data set by the mean duration of each type from Lopé (Tutin \& Fernandez, 1984; Tutin et al., 1995; also Hall et al., 1998; Brugiere et al., 1999). During long-term study at $\mathrm{BH}, 15$ per cent of fresh nest-sites consisted entirely of zero nests, likely to disappear within 4 days ( $n=147$ fresh nest-sites), whereas 85 per cent of nest-sites had at least one constructed nest. Although the frequency of zero nests at RDS may result in underestimates of group size during surveys (Remis, 1993), the nest-sites should be recognizable and have a mean duration of 66.9 days.

\section{Discussion}

\section{Human activity patterns and wildlife abundance}

Hunters make extensive use of the reserve zones in the Dzanga-Sangha Reserve for both local consumption and export to nearby urban centres (Noss, 1997). During this survey, encounter rates with sign of humans and hunting were much less frequent in the remote park sector than in other zones. Furthermore, hunting around water courses and the use of illegal snares in the hunting zone closest to the population centre appeared to be more intense than in the remote hunting zone, where trail sign, observation and information from informants indicated that guns were commonly used.
The $\mathrm{BH}$ park site has been frequently inhabited by researchers since 1988; their presence as watchful eyes and ears has, undoubtedly, reduced the levels of hunting in this area. Nevertheless, poaching within the immediate vicinity of the camp appears to be on the rise (M. R., pers. obs.). The deterrent effect of the researchers may be waning as hunters become accustomed to their presence. Furthermore, the limited punitive measures taken by the park guards, typically restricted to confiscation of meat and inexpensive cable snares, do not appear to prevent poachers from re-inhabiting former hunting areas.

Encounter rates with wildlife sign were lower in the reserve hunting zones, especially in the zone closest to villages, than the more protected and remote national park. Duikers are the main target of net, snare and gun hunters and, although sample sizes are small, duiker sign appeared scarce in the managed hunting zone closest to the village. More information is needed on

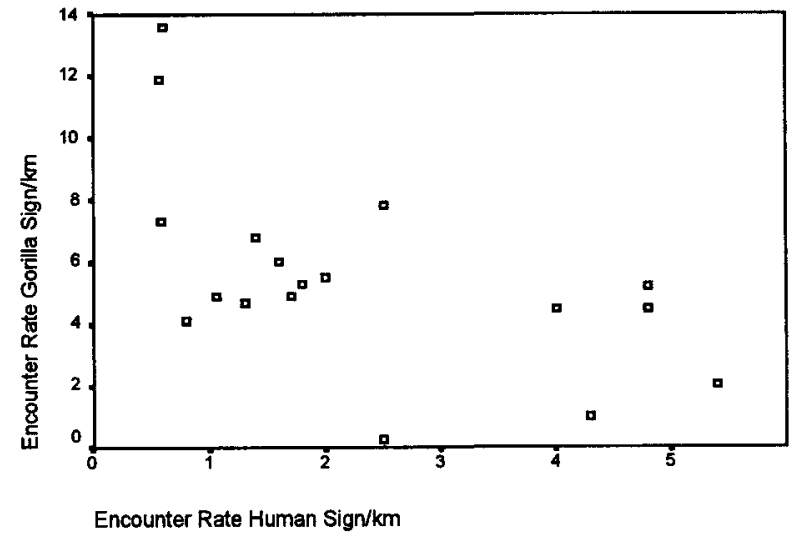

Fig. 2 Gorilla sign and human activity on line-transects, DzangaSangha Reserve, Central African Republic. Pearson's correlation coefficient $r=0.562, P<0.15, n=18$ transects. 
Table 4 Estimates of gorilla densities at Dzanga-Sangha, Central African Republic, 1997

\begin{tabular}{|c|c|c|c|c|}
\hline & Bai Hokou $(\mathrm{BH})$ park & Kongana $(\mathrm{KG})$ remote reserve & Mabongo $(\mathrm{MB})$ reserve & Total \\
\hline Total transect length $(\mathrm{km})$ & 29.9 & 25.0 & 26.3 & 81.2 \\
\hline Numbers of gorilla nests & 28 & 56 & 58 & 142 \\
\hline Numbers of gorilla nest-sites & 7 & 14 & 9 & 30 \\
\hline Mean gorilla nest-sites per $\mathrm{km}$ & 0.24 & 0.56 & 0.34 & 0.34 \\
\hline [median] & {$[0.19]$} & {$[0.51]$} & {$[0.24]$} & {$[0.24]$} \\
\hline Density of nest-sites per sq $\mathrm{km}$ & 14.03 & 20.45 & 32.24 & 21.60 \\
\hline$(95$ per cent $\mathrm{Cl})$ & $(6.0-32.7)$ & $(7.7-54.3)$ & $(12.3-84.5)$ & $(13.2-35.4)$ \\
\hline Density of gorilla nests per sq km & 56.12 & 129.5 & 111.61 & 96.85 \\
\hline $\begin{array}{l}\text { Estimated gorilla density per sq km } \\
\text { ( } 95 \text { per cent } \mathrm{CI} \text { ) }\end{array}$ & 0.84 & 1.96 & 1.67 & $\begin{array}{l}1.52 \\
(0.93-2.5)\end{array}$ \\
\hline
\end{tabular}

the duiker populations and their ecology in order to assess the sustainability of duiker consumption at RDS, but hunting rates have been suggested as unsustainable (Noss, 1997, 1998).

These results also indicate that monkeys are targets of hunters at RDS, especially near villages, where duiker sign is less common. Broad variation between sectors in encounter rates with monkeys may be related to differences in microhabitat availability as well as hunting. Nevertheless, it is also possible that where human activity is high, monkeys adopt a cryptic antipredator strategy and reduce their calling rates relative to more protected areas (also Skorupa, 1987; Hall et al., in press).

Hunting and other human activities appear to have a negative impact on elephant ranging patterns at RDS and influenced our encounter rates with elephant sign during this study (also Barnes et al., 1991). During our survey at the KG site, large 'elephant' guns were heard being fired at close range (within $2 \mathrm{~km}$ ) and an elephant fled across one of the transects. Nevertheless, it is difficult to assess the relative impacts of human hunting and distances to marshy saline 'Bai' clearings on elephant activity in these three sectors. At $\mathrm{BH}$, one of the transects crossed a large 'Bai' where elephant activity is quite high. On the other hand, the MB site is far from any clearings.

\section{Gorilla sign and nest-site densities}

Gorillas and chimpanzees are hunted increasingly in Cameroon and the Congo, especially where other wildlife is becoming scarce (Auzel \& Wilkie, in press; Muchaal \& Ngandjui, 1999). This pilot study in the Dzanga-Sangha Reserve, south-western Central African Republic, found no significant differences in gorilla nest-site encounters or densities between reserve and park sectors. There are occasional reports of gorillas caught in snares or shot by hunters in the RDS area, but if we can safely extrapolate from this small sample, gorillas do not appear to be major targets of hunters at present within these sectors of the RDS Reserve and Dzanga-Ndoki National Park.

Nevertheless, there are other indications that gorillas are affected negatively by the presence of hunters in the area. Median group sizes were largest in the hunting zone, which may reflect a safety-in-numbers antipredator strategy. Moreover, gorilla feeding sign and traces on transects were inversely correlated with indications of human activity. MacNeilage (1995) reported that the frequency of mountain gorilla sign on transects in the Virungas was inversely correlated with levels of illegal hunting and other human disturbance. Kano \& Asato (1994) reported that gorilla densities in the Congo increased with distance from nearest village. As more preferred game declines at RDS, or access to guns increases, we might expect threats to gorillas to increase,

The results of this study have further implications for the accuracy of any gorilla density calculations (including those reported here) that rely on nest decay rate data from other sites or use nest-sites older than 4 days to calculate mean group size. Nest construction type varies across gorilla habitats and may reflect density of nesting material as well as predator or hunting pressure (see also Hall et al., 1998; Brugiere et al., 1999). It is particularly important to be aware of site-specific tendencies for gorillas to nest on bare ground rather than construct a nest (zero construction) because missed nests could confound the accuracy of line-transect surveys.

Fewer zero nests were recorded in the $\mathrm{BH}$ sector during this census than in other sectors $(G=11.6, P<$ $0.05)$ or during previous long-term research at $\mathrm{BH}$ (Remis, 1993). It seems likely that during the census a higher proportion of zero nests went undetected at $\mathrm{BH}$ where few nests and nest-sites were found but gorilla sign was frequent along the transects. Nevertheless, the 
higher proportion of roadside habitats at MB indicate that the herbaceous understory there may be denser than it is at $\mathrm{BH}$ (see Ray, 1996). Microhabitat variation between study sectors in the density of herbs used by gorillas for nest construction may have affected nestconstruction patterns, and the numbers of nests found along transects.

A recent gorilla survey at Ngotto, Central African Republic, has reported low densities of herbs, a high proportion of gorilla tree nests and lower estimates of gorilla densities than at RDS (Brugiere et al., 1999). Other studies in restricted localities of Congo and Cameroon reported high herb and gorilla densities (Blake et al., 1995; Bermejo, 1997). Habitat variation in the availability of nesting material may affect local patterns of nest construction. Availability of food and nesting material may influence gorilla densities as well as confound density comparisons within and between study sites (Malenky et al., 1994; Remis, 1994; White et al., 1995; Doran \& MacNeilage, 1998; Brugiere et al., 1999).

As a result, density estimates derived from nest decay rates at other sites and mean group sizes calculated from transect results may underestimate the numbers of gorillas across the Dzanga-Sangha Reserve and elsewhere. These results highlight the need for nest decay studies to be conducted at each locality and caution when estimating ape densities from nest-counts on line transects.

Although line-transect censuses potentially underestimate the number of gorillas in groups (Remis, 1993), the results reported here accord well with group sizes and densities reported for gorillas in most other studies [G. g. gorilla: 3.6-5.3 weaned individuals per group, density $=0.88-1.6$ gorillas per $\mathrm{sq} \mathrm{km}$ (Jones \& Sabater Pi, 1971; Carroll, 1988; Fay, 1989; Fay \& Agnagna, 1992; White, 1994; Williamson \& Usongo, 1996; GonzalezKirchner, 1997; Magliocca et al., 1999 but see Bermejo, 1997; Blake et al., 1995; Brugiere et al., 1999)]. Other gorilla subspecies have similar population densities. Gorilla g. graueri density is $\mathbf{1} .26$ gorillas per sq $\mathbf{~ k m}$ (Hall et al., 1998; see also Yamagiwa et al., 1993); G. g. beringei (Virungas): 6-16 weaned individuals per group, density $=0.73-0.89$ individuals per sq km (Schaller, 1963; Harcourt et al., 1981; Murnyak, 1981; Weber \& Vedder, 1983; Aveling \& Aveling, 1987); 0.89-1.96 individuals per sq km (MacNeilage, 1995).

\section{Implications for research capacity building and conservation}

This study provided a training vehicle for Central African University students and local research assistants and has implications for conservation as well as scientific understanding of wildlife populations at RDS. Natural and social science research has been a fairly constant presence at RDS since 1987, despite economic and political fluctuations and subsequent instability of the developing ecotourism sector. Research has made significant contributions to local economic, social and educational development and should be viewed as an important tool for conservation (Saterson, 1990; Schiel, 1990; Hardin \& Remis, 1997).

Wildlife survey and census should be a major component of ongoing assessments of wildlife management and protection programmes. This preliminary study was short, and larger long-term surveys have been initiated (A. Blom, pers. comm.). Nevertheless, we now know that within RDS most wildlife sign of species targeted by hunters varies inversely with human activity, and with proximity to population centres. This study suggests that wildlife densities are likely to be lower in hunting zones than in more protected areas within the Dzanga-Sangha Reserve. These results imply that current management plans and protection efforts within integrated conservation and development zones may not always be sufficient to ensure wildlife population health in those sectors.

\section{Acknowledgements}

This work would not have been possible without financial support from World Wildlife Fund-US, Purdue University and Primate Conservation, Inc., or the permission of the Central African Government. The logistical assistance of the directors and staff of the Dzanga-Sangha Reserve, in particular, U. Ngatoua, A. Blom, J. B. Kpanou, H. Zana, A. Mbalanga, and J. P. Bambari ensured the success of this project. Z. Mogba and the Geosynergy group at the University of Bangui lent assistance to this project. Above all, I thank B. Mbassangao, H. Tcheupard, E. Ndolongbe, E. Wonga, P. Mokedi, M. Mongombe, P. Modegbe, J. P. Nyele, R. Mammao and B. Ellemo for their tireless participation in this survey. J. C. Ray and three reviewers provided useful comments on the manuscript.

\section{References}

Alpert, P. (1996) Integrated Conservation and Development Projects: examples from Africa. BioScience, 46, 845-855.

Asibey, E.O.A. (1974) Wildlife as a source of protein in Africa south of the Sahara. Biological Conservation, 6, 32-39.

Auzel, P. \& Wilkie, D. (in press) Wildlife use in northern Congo: hunting in a commercial logging concession. In Evaluating the Sustainability of Hunting in Tropical Forests (eds J. G. Robinson and E. L. Bennett). Yale University Press, New Haven. 
Aveling, C. \& Aveling, R. (1987) Report from the Zaire gorilla conservation project. Primate Conservation, $\mathbf{8}$, $162-164$.

Barnes, R.F.W., Barnes, K.L., Alers, M.P.T. \& Blom, A. (1991) Man determines the distribution of elephants in the rainforests of northeastern Gabon. African Journal of Ecology, 29, 54-63.

Bermejo, M. (1997) Study of western lowland gorillas in the Lossi forest of northern Congo and a pilot gorilla tourism plan. Gorilla Conservation News, 11, 6-7.

Blake, S., Rogers, E., Fay, M., Ngangoue, M. \& Ekebe, G. (1995) Swamp gorillas in northern Congo. African Journal of Ecology, 33, 285-290.

Brugiere, D., Sakom, D. \& Sinassonasibe, J.P. (1999) Estimation des Densites et Analyse du Comportement Nidificateur des Gorilles et Chimpanzes en Foret de Ngotto. AGRECO-GEIE, Ecofac, Central African Republic.

Bryant, D., Nielson, D. \& Tangley, L. (1997) The Last Frontier Forests: Ecosystems and Economics on The Edge. World Resources Institute, Washington, DC.

Buckland, S.T., Anderson, D.R., Burnham, K.P. \& Laake, J.L. (1993) Distance Sampling: Estimating Abundance of Biological Populations. Chapman and Hall, London.

Carroll, R.W. (1988) Relative density, range extension and conservation potential of the lowland gorilla (Gorilla gorilla gorilla) in the Dzanga-Sangha region of southwestern Central African Republic. Mammalia, 53, 309-323.

Carroll, R.W. (1997) Feeding ecology of lowland gorillas (Gorilla gorilla gorilla) in the Dzanga-Sangha dense forest reserve of the Central African Republic. PhD thesis, Yale University, New Haven, CT.

Doran, D.M. \& MacNeilage, A.J. (1998) Variation in behavior of gorilla subspecies: what's diet got to do with it? Evolutionary Anthropology, 6, 120-131.

Fay, J.M. (1989) Partial completion of a census of the western lowland gorilla (Gorilla gorilla gorilla) in southwestern Central African Republic. Mammalia, 52, 203-215.

Fay, J.M. \& Agnagna, M. (1992) Census of gorillas in northern Republic of Congo. American Journal of Primatology, 27, 275-284.

Fitzgibbon, C.D., Mogaka, H. \& Fanshawe, J.H. (1995) Subsistence hunting in Arabuko-Sokoke Forest, Kenya and its effects on mammal populations. Conservation Biology, 9, 1116-1126.

Goldsmith, M.L. (1996) Ecological influences on gorilla ranging patterns at Bai Hokou, Dzanga-Sangha Reserve. PhD Thesis, State University of New York, Stonybrook, NY.

Gonzalez-Kirchner, J.P. (1997) Census of western lowland gorilla population in Rio Muni region, Equatorial Guinea. Folia Zoologica, 46, 15-22.

Hall, J.S., White, L.J.T., Bila-Isia, I., Omari, I., Morland, H.S., Williamson, E.A. et al. (1998) A Survey of Grauer's gorillas (Gorilla g. graueri) and chimpanzees (Pan troglodytes schweinfurthi) in the Kahuzi-Biega National Park Lowland Sector and adjacent forest in eastern Congo. International Journal of Primatology, 19, 207-235.

Hall, J.S., White, L.J.T., Williamson, E.A., Inogwabini, B.-I. \& Omari, I. (in press) Distribution, relative abundance and preliminary biomass estimates for anthropoid primates within the Kahuzi-Biega Lowland Sector and adjacent forest in Eastern Democratic Republic of Congo. American Journal of Primatology.

Harcourt, A.H. (1996) Is the gorilla a threatened species? How should we judge? Biological Conservation, 75, 165-176.

Harcourt, A.H., Fossey, D. \& Sabater Pi, J. (1981) Demography of Gorilla gorilla. Journal of Zoology, 195, 215-233.

Hardin, R. \& Remis, M.J. (1997) Research and Rural Development Workshops, Bayanga, Central African Republic July 31-August 2, 1997. WWF Fund-US/BSP Conference Proceedings, Washington, DC.

Jones, C. \& Sabater Pi, J. (1971) Comparative ecology of Gorilla gorilla and Pan troglodytes in Rio Muni, West Africa. Bibliographia Primatologica, 13, 1-96.

Kano, T. \& Asato, R. (1994) Hunting pressure on chimpanzees and gorillas in the Motaba River Area, northeastern Congo. African Study Monographs, 15, $143-162$.

Laake, J.L., Buckland, S.T., Anderson, D.R. \& Burnham, K.P. (1994) DISTANCE User's Guide v.3. Colorado Cooperative Fish and Wildlife Research Unit, Colorado State University, Fort Collins, $\mathrm{CO}$.

MacNeilage, A.J. (1995) Mountain gorillas in the Virunga Volcanoes: ecology and carrying capacity. PhD Thesis, University of Bristol, Bristol, UK.

Magliocca, F., Querouil, S. \& Gautier-Hion, A. (1999) Population structure and group composition of western lowland gorillas in north-western Republic of Congo. American Journal of Primatology, 48, 1-14.

Malenky, R., Kuroda, S., Wrangham, R.W. \& Vineberg, E. (1994) The significance of terrestrial herbaceous foods for bonobos, chimpanzees and gorillas. In Chimpanzee Cultures (eds R. W. Wrangham, W. C. McGrew, F. B. M. de Waal and P. G. Heltne), pp. 59-76. Harvard University Press, Cambridge, MA.

Muchaal, P.K. \& Ngandjui, G. (1999) Impact of village hunting on wildlife populations in the Western Dja Reserve, Cameroon. Conservation Biology, 13, 385-396.

Murnyak, D. (1981) Censusing the gorillas in Kahuzi-Biega National Park. Biological Conservation, 21, 163-176.

Noss, A.J. (1997) Challenges to nature conservation with community development in central African forests. Oryx, 31, 180-188.

Noss, A.J. (1998) Cable snares and bushmeat markets in a central African forest. Enxironmental Conservation, 25, 228-233.

Oates, J.F. (1995) The danger of conservation by rural development: a case study from the forest of Nigeria. Oryx, 29, 115-122.

Oates, J.F. (1996) Habitat alteration, hunting and the conservation of folivorous primates in African forests. Australian Journal of Ecology, 21, 1-9.

Ray, J.C. (1996) Resource use patterns among mongooses and other carnivores in a Central African Rainforest. PhD Dissertation, University of Florida, Gainesville, FL.

Remis, M.J. (1993) Nesting behavior of lowland gorillas in the Dzanga-Sangha Reserve, Central African Republic: implications for population estimates and understandings of group dynamics. Tropics, 2, 245-256. 
Remis, M.J. (1994) Feeding ecology and positional behavior of western lowland gorillas at Dzanga-Sangha Reserve, Central African Republic. PhD Thesis, Yale University, New Haven, CT.

Remis, M.J. (1997) Western lowland gorillas as seasonal frugivores: use of variable resources. American Journal of Primatology, 43, 87-109.

Remis, M.J. \& Mbassangao, B. (1998) Gorilla research in the Central African Republic and preliminary results of impacts of human activities on gorillas at the Dzanga-Sangha Reserve. Gorilla Conservation News, 12, $7-8$.

Robinson, J.G. (1993) The limits to caring: sustainable living and the loss of biodiversity. Conservation Biology, 7, $20-28$.

Saterson, K. (1990) Integration of biological conservation with development policy: the role of ecological analysis. In Race to Save the Tropics (ed. R. Goodland), pp. 141-159. Island Press, Washington, DC.

Schaller, G.B. (1963) The Mountain Gorilla: Ecology and Behavior. University of Chicago Press, Chicago, IL.

Schiel, C.H. (1990) Promoting indigenous research capacities in developing countries. The International Foundation for Science (IFS) and its work. Ambio, 19, 346-348.

Siegel, S. \& Castellan Jr., N.J. (1988) Nonparametric Statistics for the Behavioral Sciences. McGraw-Hill, New York.

SigmaStat (1999) Sigma Statistical Package for Windows version 2. Jandel Software, Chicago, IL.

Skorupa, J.P. (1987) Do line-transect surveys systematically underestimate primate densities in logged forests? American Journal of Primatology, 13, 1-9.

Sokal, R.R. \& Rohlf, F.J. (1981) Biometry. W.H. Freeman and Company, New York.

Struhsaker, T.T. (1997) Ecology of an African Rain Forest: Logging in Kibale and the Conflict between Conservation and Exploitation. University Press of Florida, Gainesville, FL.

Tutin, C.E.G. \& Fernandez, M. (1984) Nationwide census of gorilla (G. g. gorilla) and chimpanzee (Pan t. troglodytes) populations in Gabon. American Journal of Primatology, 6, 313-336.

Tutin, C.E.G., Parnell, R.J., White, L.J.T. \& Fernandez, M (1995) Nest building by lowland gorillas in the Lope Reserve, Gabon: environmental influences and implications for censusing. International Journal of Primatology, 16, 53-76.

Weber, W. \& Vedder, A. (1983) Population dynamics of the
Virunga gorillas 1959-1978. Biological Conservation, 26, 341-366.

White, L.J.T. (1994) Biomass of rain forest mammals in the Lope Reserve, Gabon. Journal of Tropical Ecology, 63, 499-512.

White, L.J.T., Rogers, M.E., Tutin, C.E.G., Williamson, E.A. \& Fernandez, M. (1995) Herbaceous vegetation in different forest types in the Lope Reserve, Gabon: implications for keystone food availability. African Journal of Ecology, 33, 1.24-141.

Whitesides, G.H., Oates, J.F., Green, S.M. \& Kluberdanz, R.P. (1988) Estimating primate densities from transects in a west African rain forest: a comparison of techniques. Journal of Animal Ecology, 57, 345-367.

Wilkie, D.S., Sidle, J.G. \& Boundzanga, G.C. (1992) Mechanized logging, market hunting and a bank loan in Congo. Conservation Biology, 6, 570-580.

Williamson, E. \& Usongo, L. (1996) Gorilla survey in the Dja Reserve, Cameroun. Gorilla Conservation News, 10, 9-10.

Yamagiwa, J., Mwanza, N., Spangenberg, A., Maruhashi, T., Yumoto, T., Fischer, A. \& Steinhauer-Burkart, B. (1993) A census of the eastern lowland gorillas Gorilla g. graueri in Kahuzi-Biega National Park with reference to mountain gorillas G. $g$. beringe $i$ in the Virunga Region, Zaire. Biological Conservation, 64, 83-89.

\section{Biographical sketches}

Melissa Remis is an assistant professor of anthropology in the Department of Sociology and Anthropology, Purdue University, West Lafayette, Indiana, USA. Her main research interests focus on primate behavioural ecology and conservation, with long-term fieldwork on the feeding ecology and positional behaviour of western lowland gorillas. Currently, she is integrating field and laboratory research on the effects of body size on ape ecology and digestive strategies. She is also engaged in a multidisciplinary study of the effects of human disturbances on tropical mammals in Central African forests with an eye to further develop field training opportunities for local students. Dr Remis has published in the journals American Journal of Primatology, Primates, American Journal of Physical Anthropology, Gorilla Conservation News and Tropics, and contributed book chapters to Primate Locomotion and the forthcoming Revision of the Genus Gorilla. 